\title{
Ten Years of Realtime, Near-Surface Current Observations Supporting Oil Spill Response ${ }^{1}$
}

Robert D. Martin, Jr.

Texas General Land Office, Oil Spill Prevention \& Response, P.O. Box 12873, Austin, TX 78711-2873

Norman L. Guinasso, Jr., Linwood L. Lee III, John N. Walpert, Leslie C. Bender

Texas A\&M University, Geochemical and Environmental Research Group, 833 Graham Rd., College Station, TX 77845-9668

Robert D. Hetland, Steven K. Baum, Mathew K. Howard

Texas A\&M University, Department of Oceanography, College Station, TX 77843-3146

\begin{abstract}
Trajectory modeling is one of the few tools that allow spill managers to get ahead of an oil spill. To that end, the Texas General Land Office is committed to maintaining and improving the Texas Automated Buoy System (TABS) and its associated modeling efforts to ensure a reliable source of accurate, up-to-date information on currents along the Texas coast. As the nation embarks on the development of an Integrated Ocean Observing System (IOOS), TABS will be an active participant as a foundational regional component to the national backbone of ocean observations. The lessons-learned from TABS’ ten years of spill response operations will provide a valuable roadmap for the operators of new ocean observing systems to ensure that they understand and meet the unique needs of the oil spill response community. This paper describes the circumstances which led to the creation of TABS; the unique, spill response-driven philosophy behind the development and operation of the system; lessons-learned and the resulting modifications to the system; examples of TABS' service; new TABS forecasting models and real time analysis tools; and the future direction of TABS in the context of a national Integrated Ocean Observing System.

${ }^{1}$ This paper does not necessarily reflect the views or policies of the Texas General Land Office or Texas A\&M University. Mention of trade names or commercial products does not constitute a commercial endorsement or recommendation for use.
\end{abstract}




\section{Introduction}

In April 1995, Texas became the first state to fund and deploy a coastal network of realtime-reporting current meters to improve the data available to oil spill trajectory modelers. Ten years later, TABS remains the only system in the country with the primary mission of ocean observations in the service of oil spill preparedness and response.

TABS was built with the goal of providing trajectory modelers with timely, accurate ocean observations in an effort to improve the quality of forecasted spill trajectories early in a response. The system is comprised of a network of nine, current-measuring buoys anchored off the Texas coast (Figure 1) that report half-hourly observations every three hours under normal conditions and hourly during spill events. The TABS program also includes a forecast modeling and analysis component.

Figure 1. The TABS map (10 October 2004) showing buoy locations.

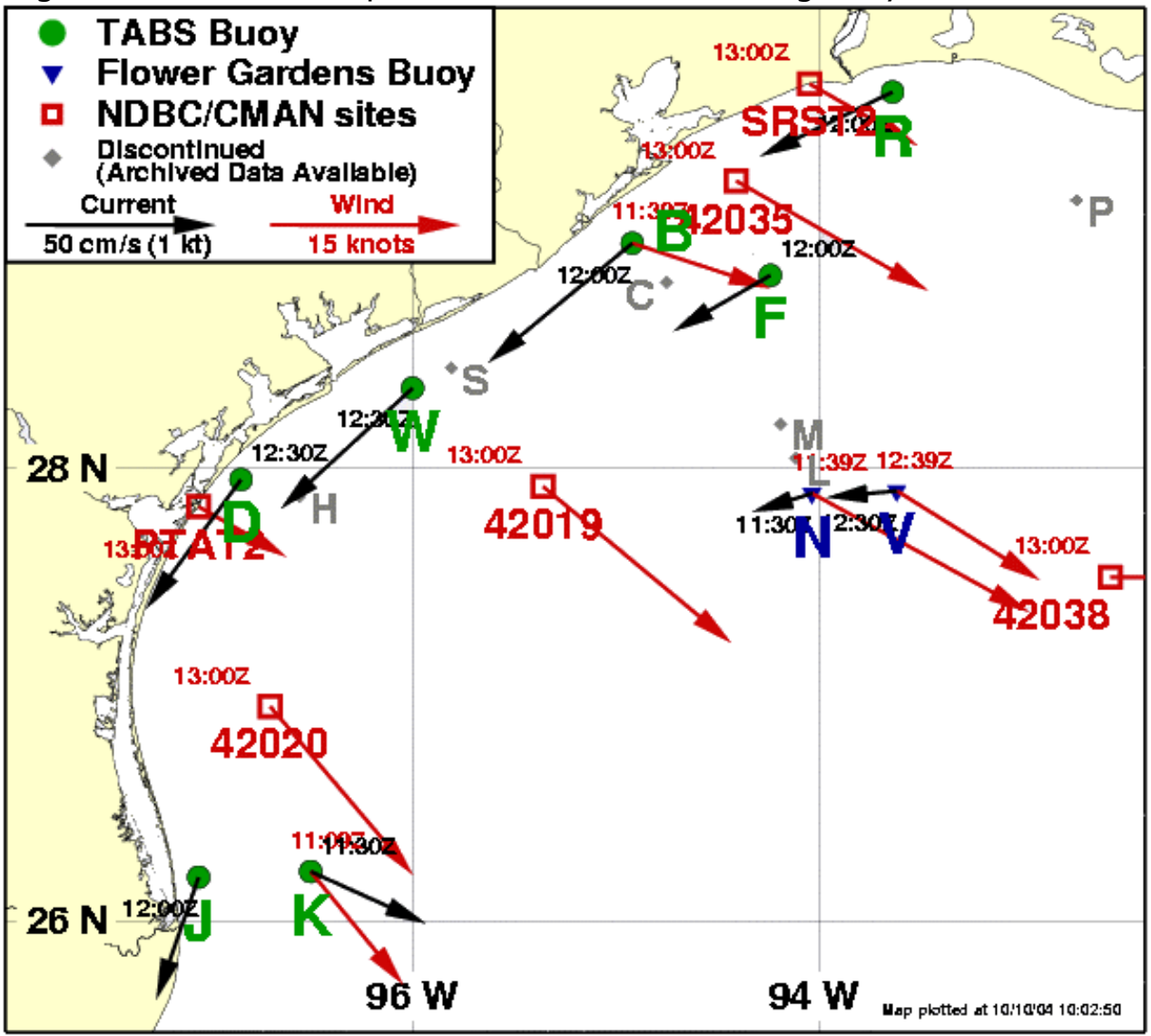


This paper describes the reasons TABS was developed; the unique, spill response-driven philosophy behind the development and operation of the system; lessons-learned and the resulting changes in hardware and operational procedures; examples of TABS' service; new TABS forecasting models and real time analysis tools; and the future direction of TABS in the context of a national Integrated Ocean Observing System.

\section{Background}

The need for a system like TABS can best be illustrated by a spill that occurred just three months prior to the first TABS buoy deployment. The Motor Vessel (M/V) Berge Banker collided with the M/V Skaubay on 5 February 1995 releasing approximately 2000 barrels of Bunker C oil into the Gulf of Mexico off Texas’ coast. Sea conditions dispersed the product offshore over a wide area and near-surface mixing made visual tracking very difficult. The few aerial observations made of the slick indicated that the product was being broken up by the rough seas and was unlikely to pose a threat to the coast. As a result, response vessels were ordered to demobilize. On 16 February 1995, an impact was reported along 18 miles of beach on Matagorda Island. Fingerprinted samples revealed that the impact to Matagorda Island was very likely the same product spilled by the M/V Berge Banker almost two weeks earlier (Lehr et al., 1997). A lack of current measurements off the Texas coast had severely limited the response community’s ability to predict the landfall of the product.

The difficulty of predicting the movement of spills like this one had plagued spill responders on the Texas coast for many years and the state’s new oil spill program decided to improve the situation. With the National Data Buoy Center (NDBC) already providing offshore wind data from a sparse array in the Gulf of Mexico, an immediate need was identified for the provision of realtime, near-surface current observations and forecasts for the offshore region. 
In 1994, the Texas General Land Office’s (TGLO) oil spill program approached Texas A\&M University’s Geochemical and Environmental Research Group (TAMU-GERG) with a description of their data needs for operational trajectory modeling. TGLO explained their requirement for a realtime, near-surface current reporting network coupled with a modeling program. To shorten the development cycle and to minimize costs, TAMU-GERG devised a plan to meet TGLO’s requirements using off-the-shelf technology. On April 2, 1995, only nine months after the project began, TAMU-GERG launched the first TABS buoy in the Gulf of Mexico 45 kilometers south of Galveston Island.

Today, there are three types of buoys (Figure 2) used in the TABS program. Type I buoys are designed for water depths of less than $40 \mathrm{~m}$ while Type II buoys are deployed in 40 to

Figure 2. Three Types of TABS buoys (left to right): 3-m discus, Type II and Type I.

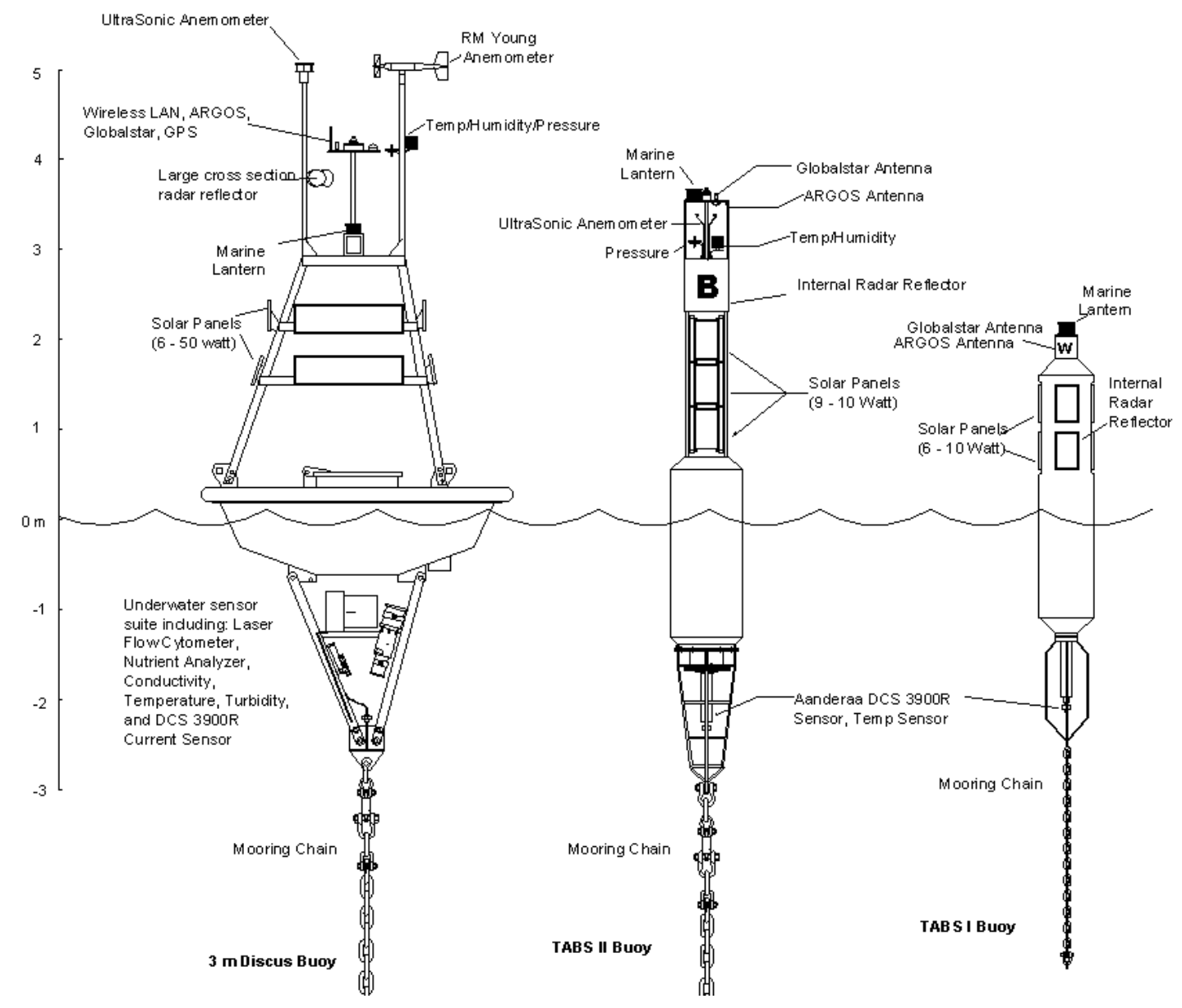


$200 \mathrm{~m}$ of water. The 3-m discus buoy provides a platform for testing new sensors and other equipment. The buoys consist of a communications link (satellite or cellular), current meter, water temperature sensor, computer system, buoyant hull, a solar-powered electrical system, and a mooring system. Some buoys are equipped with a meteorological package. A more detailed description of the TABS buoys can be found in Guinasso et al. 2001.

\section{Operational Philosophy}

From the outset, TABS has been an operationally-focussed program driven by the needs of the spill response community rather than a research-focussed program driven by the desires of the academic community. Attention to TABS' core mission is reinforced by the manner in which the program is funded. TABS' funding is provided by the State's Coastal Protection Fund, which was established by state law in 1991 by the Oil Spill Prevention and Response Act. This law enables the TGLO to assess a two-cent-per-barrel fee on crude oil loaded or off-loaded in Texas ports. The result is a direct connection between TABS' funding source and the spill response community, thus ensuring a program focussed on end-user needs.

The focus on serving the spill response community's needs has had an impact on the pace and direction of TABS' development. The operational demands on TABS necessarily limit experimentation with new equipment to small-scale tests. When the tests prove successful, implementation is slowly executed throughout the network to limit risks. The direction of development has also been constrained to the needs of the funding community. TABS has never attempted to be all things to all people. The overall result has been (1) a carefully targeted use of 
state funds that ensures community support and (2) a cautious evolution of improvement that makes the TABS buoys more akin to a sturdy appliance than to a delicate research instrument.

\section{Lessons Learned and Modifications Made}

Over the last decade, several important lessons have been learned that have increased the buoys’ survivability, reliability, and the time needed between maintenance visits.

The first improvement has been in two areas of the communications system: redundancy and reliability. Early in the program, realtime communications were sometimes curtailed because of damage to the cellular telephone antenna. This usually occurred when boats were casting off after having tied off to the buoys for fishing or other reasons. Another cause for loss of realtime data transmission was very rough seas tilting the buoys to a point where the cellular connection was dropped because a signal lock could not be maintained.

To assist with the loss of communications from antenna breakage, a backup communications system was added using Service Argos. The buoy automatically activates the backup communication system after four failed connection attempts on the primary system. This backup system has worked on several occasions and helped reduce the frequency of maintenance visits to the buoys.

The second communications improvement helped with both of the original problems (i.e., antenna breakage and loss of signal lock). In the spring of 2001, the TABS program began a system-wide changeover from the offshore cellular telephone system (which used a high profile, antenna) to a satellite telephone system using a low profile antenna with an omnidirectional beam pattern. The system selected was the Globalstar USA, Inc. satellite communications service using a Qualcomm GSP-1620 packet data modem (Walpert et al. 2002). The reasons for 
changing communications systems are that the antenna's low profile housing is not as subject to breakage, the omnidirectional beam pattern allows the system to maintain a signal lock even if the buoy is laying on its side, and the low earth orbit satellite constellation avoids line-of-site signal problems. Since the changeover, TABS has not suffered a single communications failure with this newer system in the field. In addition, the satellite telemetry service is half the cost of the original cellular service.

Another improvement to TABS was in the area of current meters. The Marsh-McBirney model 585 electromagnetic sensors used early in the program proved sensitive to marine fouling and water leakage. A field test conducted by TAMU-GERG in 2000 convinced TABS managers that the Aanderaa DCS3500R Doppler current meter (a point measurement sensor, not a profiler) would resolve these issues (Walpert et al., 2001).

The changeover to the new Aanderaa sensor began in the spring of 2001 and the result has been high data quality and reliability. The program has experienced only two failures due to fouling and both of those occurred when the buoy had been in the water for over seven months at TABS site $\mathrm{R}$ which has the highest rate of marine growth of all the TABS sites. In addition, there has only been one major mechanical failure in the field where the sensor began reporting currents that were approximately 135 degrees off due to a compass failure.

Another improvement in reliability came about after Hurricane Brett caused the loss of a TABS II buoy in August of 1999. Following recovery of the buoy on a beach one year later, it was discovered that the buoy had been sunk and the electronics chamber had been flooded. The flooding was the result of water entering the buoy system through the cables, which had been damaged during the hurricane. Following the hurricane, all watertight glands were replaced with 10,000 psi rated bulkhead connectors and pigtails. Since this conversion, the TABS 
program has not had an incident where water has entered the electronics chamber, even following severe collisions with ships at sea. In a very striking example, one buoy, sunk in 100 m of water by Hurricane Claudette, was recovered only to discover that not only was the electronic chamber still dry, but the buoy continued to operate and collect data for a number of weeks while submerged. This system was re-deployed at the same location within two months after being retrieved from the bottom. The cause of this buoy sinking in the first place (an inadequate mooring design) has since been redesigned to allow the buoys to survive 30-foot seas and 100-knot winds.

\section{Service to the Public}

At 1320 hours on 18 March 1996, Buffalo Marine Barge 292 suffered structural damage in the Houston Ship Channel near the Gulf of Mexico entrance to Galveston Bay. As a result, the barge spilled 3000 barrels of an intermediate fuel oil (i.e., IFO 380) into the bay. Northerly winds drove the oil from Galveston Bay into the Gulf of Mexico where an upcoast (to the northeast) current combined with the winds to carry the slick offshore and to the southeast. A southerly wind changed the trajectory to the northeast thus threatening Sabine Pass on the TexasLouisiana border. Planners went to work to devise a protection strategy for Sabine Pass in anticipation of the impact. On 24 March 2004 at 0200 UTC, the TABS data showed a sudden current reversal back to the southwest (Figure 3) ... a flow regime more typical for that time of year (Lehr et al., 1997; Martin et al., 1997; Guinasso et al., 2001). Working closely together, TGLO's and NOAA's trajectory modelers determined that the downcoast flow would hold for many more days taking the oil to the southwest and away from Sabine Pass. By revealing the current reversal within two hours of its occurrence and 24 hours before it would have otherwise 
been known without TABS observations, the buoy system allowed responders to abandon their plans for Sabine Pass and refocus their efforts on Galveston Island and Bolivar Peninsula. Had the protection plans been executed over that 24-hour period, an estimated \$225,000 would have been wasted on an unnecessary deployment in an attempt to protect an area no longer at risk.

Figure 3. Buffalo 292 oil spill trajectory. Currents for buoys B, C, D, and F (top to bottom) are illustrated as stickplots in the inset in the upper left.

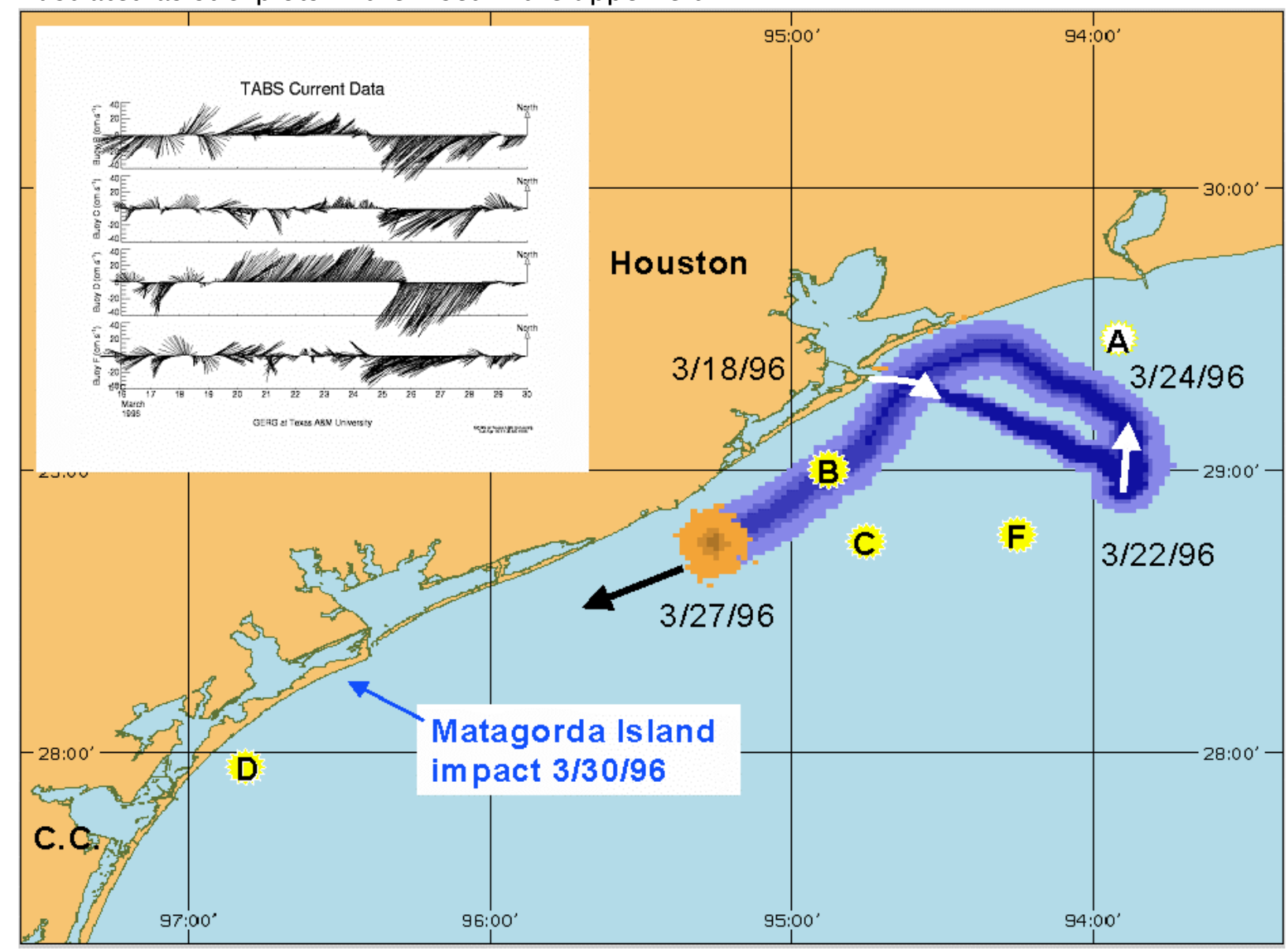

Since the first TABS buoy deployment to the time of this writing, spill responders have accessed TABS data for decision-support in more than two dozen spills. Table 1 provides a list of those spills as documented by the NOAA Office of Restoration and Response.

An example of the spill response community's acceptance of the TABS concept is the joint industry project funded by 16 offshore operators to maintain two TABS buoys at the Flower 
Garden Banks Marine Sanctuary. These buoys (see buoys N and V in Figure 1) provide current and wind observations to the operators in the event that they need the data to respond to a spill in this sensitive area.

Table 1. TABS has provided data for the following offshore spill events (N. Scillo 2004).

\begin{tabular}{|l|l|}
\hline $1996-$ & Barge Buffalo 292 \\
\hline $1998-$ & T/V Western Lion \\
& Lightering Spill \\
& Texas Coast Mystery Slick \\
& Natural Gas Platform \\
& F/V Miss Conch \\
& Freeport Sunken Vessel \\
& T/V Somerset \\
& M/V Violetta \\
\hline $1999-$ & Tug Miss Jessica \\
& $\begin{array}{l}\text { T/V Sea World } \\
\text { Blue Master }\end{array}$ \\
\hline $2000-$ & $\begin{array}{l}\text { Freeport Mystery Spill } \\
\text { F/V Gulf Dipper } \\
\text { Superior Conquer }\end{array}$ \\
\hline $2001-$ & $\begin{array}{l}\text { New Field Platform } \\
\text { Jack Rig Marine 4 } \\
\text { Mystery Slick }\end{array}$ \\
\hline $2003-$ & $\begin{array}{l}\text { Mystery Slick Offshore Galveston Jetty } \\
\text { M/V Peljesac }\end{array}$ \\
\hline Annual* - & $\begin{array}{l}\text { tarball impacts on south Texas barrier islands associated with spring current } \\
\text { reversals observed 1998 to present }\end{array}$ \\
\hline
\end{tabular}

*These events are found in state records, but are not recorded in the NOAA database.

TABS has also been of service beyond Texas shores. In the winter of 2001, the submarine USS Greeneville accidentally surfaced beneath the Japanese training vessel Ehime Maru sinking the ship and sending nine crew members to their deaths. In an effort to recover the crew's remains, the U.S. Navy launched a recovery mission in the summer of that same year. At the Navy's request, TGLO loaned two TABS buoys to the recovery effort. TAMU-GERG personnel easily modified the two buoys (a Type I and a Type II) with the addition of an acoustic Doppler current profiler (ADCP) in preparation for the Navy deployment. The TABS buoys 
provided data for both diving conditions and spill response (in the event that one of the vessel's fuel tanks ruptured during the recovery operation).

There are also instances of TABS service unrelated to spill response. One example is TABS’ participation in the Monitoring and Event Response for Harmful Algal Blooms (MERHAB) project, which is testing experimental sensors (e.g., an imaging flow cytometer) to identify the onset and precursors of harmful algal blooms off the Texas coast. Another example is TABS' cooperation with the National Data Buoy Center in which TABS current and wind observations are provided to NDBC for QA/QC and included in the Global Telecommunications System (GTS) for worldwide distribution. An indicator of TABS popularity beyond the spill response community can be found in the increase in visits to the TABS website (Figure 4) since 1995. Given the limited size of the trajectory modeling community, it is very likely that most of these website accesses are related to activities other than oil spill response.

Figure 4. TABS quarterly website access statistics.

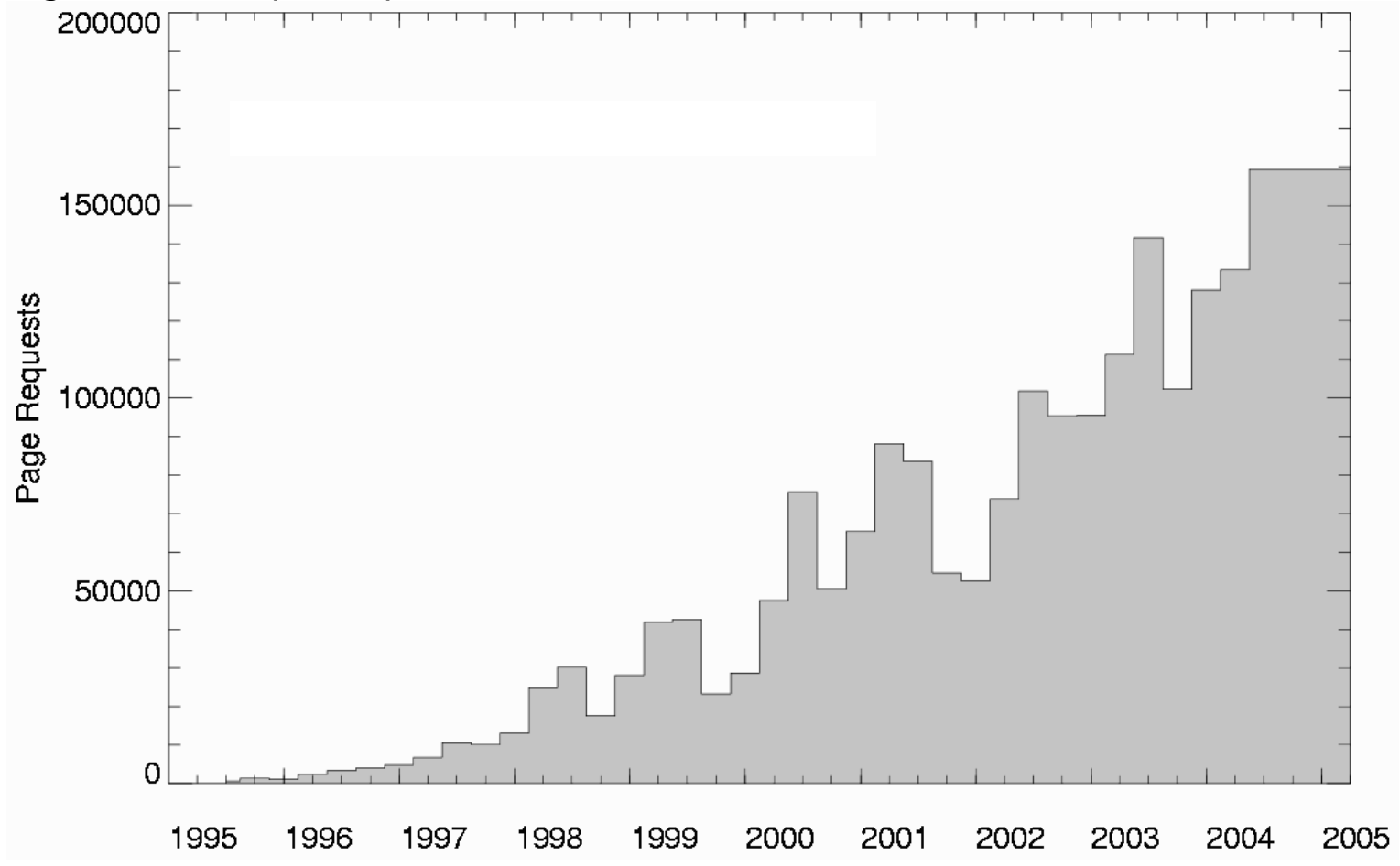




\section{Tools for Trajectory Modelers}

The TABS website is the first access point for trajectory modelers (and the public) to the TABS data. By design, a visitor to the website is presented with an overview map of the currents and winds off the Texas coast (see Figure 1). From this map, visitors can browse data from individual buoys in either graphic or tabular format.

The TABS surface current prediction system attempts to save trajectory response time by maintaining hydrodynamic models in a constant state of readiness should the need for a current forecast arise.

The original shelf circulation model, developed and maintained by Dr. Joseph Yip from 1998-2002, consisted of a 3-D version of the Princeton Ocean Model (POM) adapted to perform simulations on the northern shelf on a domain extending from $25^{\circ} \mathrm{N}$ on the Mexican coast to $85^{\circ} \mathrm{W}$ at the coastline of Florida. The operational POM model is a simplified barotropic version that produces a 24-hour surface current prediction simulation.

The second generation TABS modeling system uses the Regional Ocean Modeling System (ROMS) as the ocean circulation model component. The improvements available with ROMS include an improved physical parameterizations of ocean processes, built-in parallelization allowing simulations to be run on many machines simultaneously, and improved and more flexible code structure for model input data and output files.

Both models (POM and ROMS) are currently run on a daily basis by Texas A\&M University's Oceanography Department. Model output is publicly available on the Internet (see Internet Resources).

The newest addition to the TABS suite of experimental products is the Real Time Analysis (RTA) website. This website provides a variety of statistical visualization products 
from the TABS current observations including: stickplots, scatter plots, current roses, de-tided currents, and along-coast variability histograms. The intent is to provide trajectory analysts with visualizations of current variability within the context of both short- and long-term time frames.

\section{The Future}

The future of TABS will see a continuation of efforts to add meteorological sensors and ADCPs to every TABS buoy. The ability to do this has already been proven in field deployments and is only limited at this time by funding. The additions will help by (1) increasing the density of offshore meteorological observations and (2) providing the third dimension needed for data assimilation in the TABS forecast modeling efforts. The addition of downward-looking ADCPs to the buoys carries the added advantage of avoiding problems common to upward-looking, bottom-mounted ADCPs associated with platform deployments (i.e., severed power/data cables, sensor burial, and divers required for maintenance).

In the area of modeling, the emphasis will be on testing the skill of both models using hindcasts of surface currents and coastal sea level. These two parameters are affected by different dynamics, therefore each measures different qualities of the models ability. The two biggest challenges for the TABS models are reproducing the phase of the observed inertial oscillations and reproducing the coastal sea level as affected by fresh water inputs. The plan is to address these issues and increase model skill by including better representations of the density field, both in terms of the surface mixed layer due to solar heating and buoyancy driven flow along the coast due to riverine inputs. 


\section{Conclusion}

As the nation embarks on the development of an Integrated Ocean Observing System, TABS will be an active participant as a regional coastal ocean observing system component and the primary source of near surface current measurements in the northwestern Gulf of Mexico. In addition to serving as a primary data source, TABS will provide high quality, in-situ field validation for forecast models and ancillary, remotely sensed observations such as hf radar. The lessons-learned over ten years of TABS operations will provide a valuable roadmap for new ocean observing systems and their operators to ensure that they understand and meet the unique needs of the oil spill response community.

TABS was built to provide spill responders with offshore current measurements within the first few minutes of an oil spill and to improve the reliability of trajectory modeling by improving the quality and timeliness of current data to drive these models. A continuous effort of improvement coupled with an unwavering commitment to TABS’ operational philosophy and attention to end-user needs will ensure that these goals continue to be met for the spill response community for another 10 years.

\section{Acknowledgements}

We thank Greg Pollock (Deputy Commissioner for Oil Spills, TGLO) and Jerry Patterson (Commissioner, TGLO) for their continued support of the TABS program.

\section{Biography}

Robert D. Martin, Jr., Ph.D., is the state scientific support coordinator for TGLO’s Oil Spill Prevention and Response program. He provides on-scene technical and scientific support to the state's oil spill response activities including serving as the state's trajectory modeling team leader and the TABS program manager for TGLO.

\section{References}

Guinasso, N.L., Jr., L.C. Bender, III, L.L. Lee, III, J.N. Walpert, J. Yip, R.O. Reid, M. Howard, D.A. Brooks, R.D. Hetland, and R.D. Martin (2001). Observing and Forecasting Coastal Currents: Texas Automated Buoy System (TABS) in OCEANS 2001 MTS/IEEE Proceedings, 1318-1322, Marine Technology Society, Washington DC. Presented by Norman Guinasso 8 November 2001 at Oceans 2001 Meeting in Honolulu, HI. 
Lehr, B., D. Simecek-Beaty, D. Payton, J. Galt, G. Watabayashi, R.D. Martin, and R. Solis (1997). Trajectory Prediction for Barge Buffalo 292 Spill. Proceedings, 1997 International Oil Spill Conference. Americn Petroleum Institute, Washington, DC. pp. 25-33.

Martin, R.D., Jr., F.J. Kelly, L.L. Lee, and N.L., Guinasso, Jr. (1997). Texas Automated Buoy System: Real-Time Currents for Oil Spill Response. Proceedings, 1997 International Oil Spill Conference. American Petroleum Institute, Washington, DC. pp. 75-78.

Scillo, N., NOAA Office of Response and Restoration, email communication 21 June 2004.

Walpert, J.N., N.L. Guinasso, Jr., Leslie C. Bender, Linwood L. Lee III, and F.J. Kelly (2001). The Effects of Marine Fouling on the Performance of a Single-Point Acoustic Doppler Current Sensor Mounted on a TABS-II Spar Buoy in OCEANS 2001 MTS/IEEE Proceedings, 956-961 Marine Technology Society, Washington DC.

Walpert, J.N., N.L. Guinasso, Jr., and L.L. Lee, III (2002). High speed two way data communications used in the Texas Automated Buoy System (TABS) in OCEANS 2002 MTS/IEEE Proceedings 1001-1006, Marine Technology Society, Washington, DC. Presented by John Walpert on 30 October 2002 at Oceans 2002 Meeting in Biloxi, MS.

Yip, K.J., L.C. Bender, III, \& R.O. Reid (2004). Estimation of a Shelf-Wide Circulation Field from Sparse, Coastal Current Meter Data, to be submitted to J. Phys. Ocean.

\section{Internet Resources Cited in this Paper}

TABS Observations http://tabs-os.gerg.tamu.edu/tglo

TABS POM Output http://seawater.tamu.edu/tglo/

TABS POM Output via Live Access Server http://saltwater.tamu.edu:8080/las/servlets/dataset

TABS ROMS Output http://seawater.tamu.edu/tglo/rindex.html

TABS Real Time Analysis (RTA) http://tabs.gerg.tamu.edu/ les/RTA/RTA_index.html

NOAA OR\&R Historical Incidents Search Page

http://www.incidentnews.gov/incidents/history.htm 